\begin{tabular}{c|c}
\multirow{2}{*}{ EESD'15 } & The $7^{\text {th }}$ International Conference on Engineering Education for Sustainable Development \\
\cline { 2 - 2 } & Vancouver, Canada, June 9 to 12, 2015
\end{tabular}

\title{
AN EDIBLE EDUCATION IN SUSTAINABLE DEVELOPMENT: INVESTIGATING CHOCOLATE MANUFACTURING IN A LABORATORY- BASED UNDERGRADUATE ENGINEERING COURSE
}

\author{
Alexander V. Struck Jannini ${ }^{1}$, Christian Wisniewski ${ }^{1}$, Mary M. Staehle ${ }^{1}$, Joseph F. \\ Stanzione $\mathrm{III}^{1}$, and Mariano J. Savelski, ${ }^{1,2}$ \\ ${ }^{1}$ Rowan University, United States of America \\ 2 savelski@rowan.edu
}

\begin{abstract}
Green engineering, sustainability, and sustainable development are topics of great import to all engineering disciplines. To introduce students to these topics, hands-on experiments were developed for inclusion within a multi-disciplinary freshman engineering course. In these experiments, students learned to produce chocolate truffles and, ultimately, challenged to analyze and optimize the sustainability of the process with a cradle-to-gate and social life cycle assessments. Student analyses incorporated waste management strategies, overall energy and material consumption calculations, carbon reduction strategies, the use of engineering software, and the importance of fair trade in this industry. Eighty-nine freshman engineering students at Rowan University completed the experiments. Pre- and post-tests were used to evaluate the effectiveness of the course on increasing student knowledge of sustainability, of sustainable development, and of the impact engineers can have on socioeconomics. Preliminary results indicate that the course was effective in enhancing student knowledge and awareness of the social and environmental implications of chocolate manufacturing. A complete analysis and description are presented in this paper.
\end{abstract}

\section{INTRODUCTION}

The continued use and depletion of non-renewable resources warrant critical efforts to drastically improve the sustainability of current manufacturing processes. In response, engineering communities have begun discussing ways to increase the sustainability of current manufacturing processes and everyday lifestyles. This process, also known as sustainable development, is used to determine ways of meeting the needs of the present without compromising future generations to meet their own needs (Brundtland 1987). This broad definition has allowed sustainable development to be implemented in several different fields. Sustainable development is now embraced by companies, governments, social reformers, and environmental activists, who each have their own interpretation of what sustainable development means (Giddings, Hopwood and O'Brien 2002).

For engineers, sustainable development is defined to include process development. Aspects that are often discussed in regards to sustainable development in an engineering setting include the conservation and improvement of natural ecosystems, minimizing the depletion of renewable and non-renewable natural resources, waste prevention and management, and the improvement of technologies (Hesketh, et al. 2004). Mathematical and computational tools have been developed to model the impact of such aspects on industrial processes. One such modeling tool is a Life-Cycle Analysis (LCA). An LCA is defined as an evaluation of all inputs and outputs of a process to determine the environmental impacts 
that are associated with it (Guinée, et al. 2002). An LCA can include, but is not limited to, all stages of a manufacturing process, including the extraction of resources, the production of raw materials, the product processing, the use of the product, and its disposal (Guinée, et al. 2002).

With the increased interest in sustainability and sustainable development, pedagogical researchers have developed methods of incorporating sustainability into engineering curriculums (Perdan, Azapagic and Clift 2000, Fenner, et al. 2005, Elnashaie, et al. 2013). Recently, a team in Malaysia discussed methods of implementing sustainable development into chemical and biological engineering curricula, using both centralized and decentralized approaches. The centralized approach involved adding sustainable development concentrations to the major, and adding new courses that related to sustainable development engineering. The decentralized approach involved changing the structure of the "core" courses so that they focused on aspects of sustainable development. Based on these approaches, the team created feasible ways to incorporate sustainable development engineering into the chemical and biological engineering department at Princeton University. Although there has been significant research to incorporate sustainable development into engineering curricula, there has been considerably less research in incorporating LCAs into engineering education. Evans, Galvin, and Doroodchi developed two LCA example problems that can be used in a chemical engineering curriculum. The two examples, an investigation in which method is better to use for drying hands and a study on the proper location for a manufacturing plant, can be used in first year engineering courses (Evans, Galvin and Doroodchi 2008). They found that student feedback to the exercises was favorable, and that they showed increased appreciation for the viewpoints of others, and a willingness to apply their own interpretations based on assumptions. Another example of LCA incorporation into an engineering curriculum involved biodiesel production. This project involved first year engineering students creating biodiesel, and then performing an LCA to compare its production to that of traditional petroleum-based diesel (Farrell and Cavanagh 2014). Their assessment showed an increased conceptual understanding of the LCA process and an average gain of $55 \%$ in knowledge about LCA's.

In this paper, we briefly describe experiments for use in an introductory multi-disciplinary engineering course that focused on sustainable development of chocolate manufacturing. Specifically, the experiments focused on producing chocolate truffles while exposing students to engineering concepts such as waste and waste management, energy requirements, and physical property measurements. Chocolate manufacturing was chosen not only to keep student interest high, but also because of negative socioeconomic factors surrounding the industry. The cocoa production sector has been tied to child trafficking for decades (Nagle 2008). More recently, child labor has grown in West and Central Africa (where the majority of cocoa is farmed) due to a demand for larger profits (LaFraniere 2006). Child slavery and its ties to cocoa harvesting is not frequently considered by chocolate consumers, and as such can stimulate important discussions on social responsibility in manufacturing. Since the course was an introductory course, the experiments also incorporated aspects of general engineering education, such as working individually and in teams to solve engineering problems, designing and conducting experiments, and also analyzing and interpreting data (Accreditation Board for Engineering and Technology 2013). The experiments also required the students to conduct an LCA on the chocolate manufacturing process, prompting them to discuss ways to minimize food waste, to lower energy consumption, and to use sustainable, socially beneficial raw products. The purpose of this paper is to convey our preliminary results that indicate students gained knowledge and awareness of the social and environmental implications of chocolate manufacturing.

\section{EXPERIMENTS}

Experiments were developed to teach students about sustainable development and chocolate manufacturing processes. The course was designed to be a multi-disciplinary course that introduces students to engineering through active learning activities, i.e. project-based team laboratory experiments (Farrell, et al. 2001). Therefore, the experiments were designed to tie together introductory engineering concepts and the sustainable development objectives. The experiments had students work in multidisciplinary teams in order to complete the objectives of each lab. The first and seventh experiments were held in a standard computer lab, while the second through sixth and last experiments were held in a food-grade laboratory that contained cooking equipment and food-grade raw materials. Conducting most 
of the experiments in a food-grade laboratory enabled the students to gain good manufacturing practices and obtain hands-on practical lab experience, all while being able to sample their chocolate truffles.

The first lab of the semester had students conduct research on LCAs and the chocolate manufacturing process. Students used online resources, such as the journal databases provided through library services. The second lab of the semester guided students to create chocolate ganache domes using couverture dark chocolate (chocolate made with extra cocoa butter) and heavy cream. Students measured the mass of raw ingredients in the beginning of the experiment, and then measured the mass of the ganache domes. Students were to see that the masses did not match, and to speculate why that was the case using a mass balance. Using mass balances was also reinforced through an exercise in which students calculated the nutritional information of their ganache domes from the nutritional values of the raw ingredients.

The third experiment introduced students to the tempering process of chocolate and energy balances. Tempering chocolate is the process by which chocolate is heated and agitated in order to recrystallize the fats and oils. Through this process, chocolate gains qualities such as sheen and brittleness that are considered desirable in chocolate products (Afoakwa, et al. 2008). Students were tasked with manually tempering chocolate and using watt-meters to determine the energy requirements for the process. Energy requirements included the energy needed to boil water, the energy needed to melt chocolate, and the energy needed to maintain an elevated temperature. The fourth lab of the semester introduced students to a tempering machine, which controls the temperature of the chocolate automatically, reducing the likelihood that the chocolate will overheat. (Overheating at any point requires reinitiation and repetition of the tempering process.) Students compared the energy requirements for the tempering machine to that of manually tempering. The fourth lab also asked the students to conduct a statistical analysis on chocolate truffle products consisting of a dark chocolate ganache center enrobed in tempered milk chocolate. Students were asked to find the average and standard deviation of the ganache centers before and after enrobing. Students saw that their standard deviation increased after enrobing. This gave students insight into which processes in chocolate truffle manufacturing require extensive waste management and which require quality by design considerations.

The fifth experiment introduced the students to developing and utilizing empirical relationships. Students were given three chocolate samples of various cocoa percentages (33.4\% to $90 \%)$ and one sample of unknown cocoa percentage $(70 \%)$. The students were asked to determine the cocoa percentage of the unknown sample using several techniques, including: developing correlations based on melting point and absorbance in olive oil at $615 \mathrm{~nm}$, and a taste test. In the taste test, a student would rate sweetness and bitterness on a scale of $1-10$, with 1 being very little and 10 being very much. Students were then asked which test they felt was the most accurate and why. The sixth experiment was another investigation into energy requirements. This time, students had to find the energy required to melt various chocolate products. White, milk, and dark chocolate varying from $54 \%$ to $90 \%$ cocoa were used. To determine the energy required to melt the chocolate, students added boiling cream to chopped chocolate in increments and used a simplified heat transfer equation to calculate the heat transferred to the chocolate based on the volume of heavy cream required to melt the chocolate.

The seventh experiment was developed to introduce students to sustainability software. Students were given a tutorial on SimaPro ${ }^{\circledR}$ and then tasked with finding life cycle inventory $(\mathrm{LCl})$ data for different raw ingredients that were found in common chocolate products. The $\mathrm{LCl}$ data was then used in the final experiment of the semester.

For the final experiment, students were required to produce their own chocolate truffles. Each team created a unique, final chocolate truffle that would appeal to consumers and also meet sustainability requirements, such as low energy usage and waste management. The students were also asked to consider social awareness (i.e. socially responsible manufacturing of raw ingredients). An example of final truffle products is shown in Figure 1. Teams were evaluated on their implementation of these different areas with a team presentation, where they were charged with presenting their chocolate truffle to a panel of instructors who acted as a chocolate manufacturing plant management team that was interested in all aspects of producing their delectable, including taste. Students were graded based on 
the information that they presented and their answers to questions provided by the panel. The taste of the final truffle product was not considered as part of their grade.

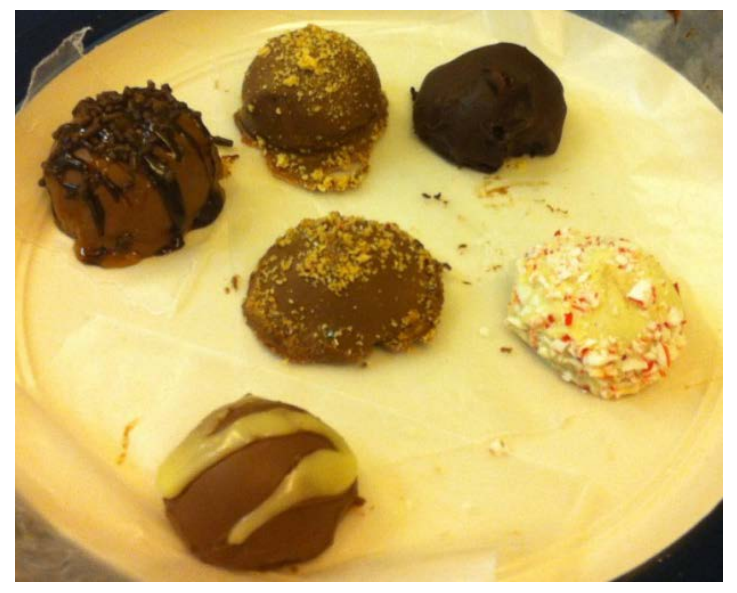

Figure 1: Sample truffle products made by students for the final lab. Students were allowed to choose from a variety of chocolate (white, milk, and dark) and were given the liberty to use extra ingredients (sprinkles, graham crackers, peppermint candies, etc.).

\section{ASSESSMENT}

In order to gauge student learning of sustainable development, assessments were used both at the beginning and at the end of the semester. The assessment instrument consisted of two parts: a LikertScale survey used to determine student opinions, and a multiple-choice/true-or-false section used to determine student learning.

In the Likert-Scale portion of the assessment, students were asked to agree or disagree with a set of statements. Using this scale, an answer of "1" means the student "strongly disagrees" with the statement; alternatively, a response of " 5 " means the student "strongly agrees" with the statement. Students were asked questions in regards to sustainability concepts and socioeconomics. Six statements from the Likert-Scale portion are shown in Table 1, along with the percent increase of the average response from pre-semester to post-semester. The results of these six statements are shown in Figure 2. A two-tailed paired Student's t-test was used to determine if the post-assessment data was statistically different from the pre-assessment data. For five of the six statements, it was determined that the post-semester assessment data was significantly higher than that of the pre-semester assessment $\left(p<1^{*} 10^{-3}\right)$. Question 4 saw no significant change $(p=0.325)$. While we would have liked to have observed a significant decrease in this answer, we consider it to be still desirable that the students generally disagree with this statement, since due to variation in the manufacturing of individual entities, nutrition labels are not $100 \%$ precise. Overall, we found that the students were more confident in their knowledge of sustainable development, socioeconomics, and the engineering role in these areas. 
Table 1: Six representative questions from the Likert-Scale assessment, and the percent increase in the average response for each question.

\begin{tabular}{|c|c|c|}
\hline Number & Statement & Percent Increase (\%) \\
\hline 1 & $\begin{array}{l}\text { I know what a life cycle } \\
\text { assessment (LCA) is and what it } \\
\text { is used for. }\end{array}$ & 196 \\
\hline 2 & $\begin{array}{c}\text { I know what a social life cycle } \\
\text { assessment (s-LCA) is and what } \\
\text { it is used for. }\end{array}$ & 212 \\
\hline 3 & $\begin{array}{l}\text { I know where mass and energy } \\
\text { are lost in the production of } \\
\text { chocolate truffles. }\end{array}$ & 205 \\
\hline 4 & $\begin{array}{l}\text { Nutrition label on food are } 100 \% \\
\text { precise }\end{array}$ & 6.19 \\
\hline 5 & $\begin{array}{l}\text { It is important that chocolate } \\
\text { manufacturers use renewable } \\
\text { energy resources during } \\
\text { production }\end{array}$ & 13.4 \\
\hline 6 & $\begin{array}{l}\text { Engineering plays an important } \\
\text { role in the everyday production of } \\
\text { chocolate. }\end{array}$ & 8.69 \\
\hline
\end{tabular}

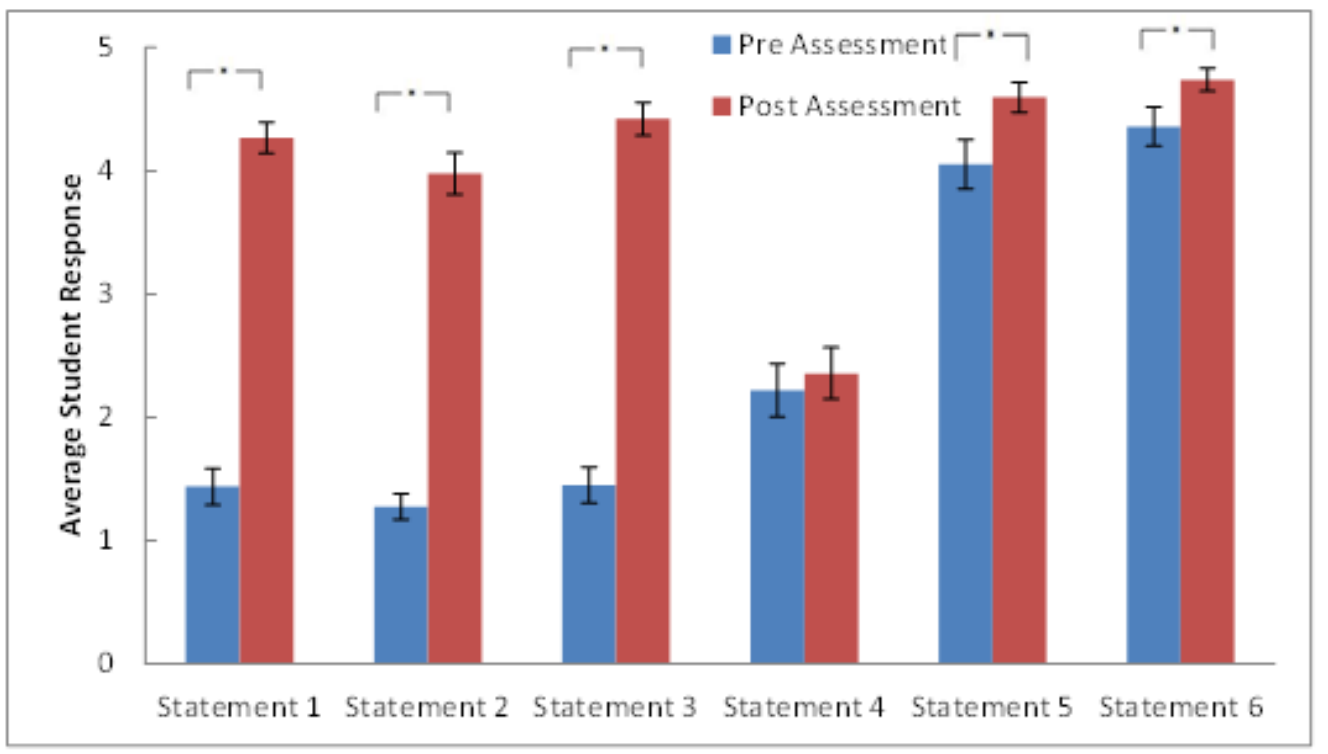

Figure 2: The results of the Likert-Scale assessment. The statement numbers correspond to the statements in Table 1. The error bars are $95 \%$ confidence intervals. The * indicates that the pre- and post-assessment data is statistically different, with a p-value $<0.05$.

For the multiple-choice/true-false section of the assessment, students were asked questions regarding similar aspects to those discussed in the Likert-Scale portion. Sample questions can be seen in Table 2. Table 2 also contains the percent increase of correct responses from pre- to post- semester responses. Figure 3 shows the percent correct responses for the questions shown in Table 2. A two-tailed, onesample Student's t-test was used to determine whether there were significant changes between pre- and post- semester responses. While we observed a significant increase in Questions 1, 3, and 4, Question 
2 did not have a significant difference between pre- and post-semester results. This differs from the results of the Likert-Scale portion of the assessment for this topic. From the Likert-Scale results, it would seem that students feel confident in their ability and knowledge of sustainability and sustainable development, but from the multiple-choice/true-false section, the results show that students are not able to correctly define sustainability as it relates to engineering. Another interesting finding from the multiplechoice/true-false section is that students had a high percentage of correct responses in the pre-semester test for Question 1. We hypothesize that this is due to the wording of the question and its possible answers. The correct response for this question was the only possible answer that contained the word "assessment" in its answer. Therefore, we think that students most likely determined it to be the correct response by the process of elimination.

Table 2. Sample questions from the multiple-choice/true-false portion of the assessment. Included is also the percent increase of correct responses.

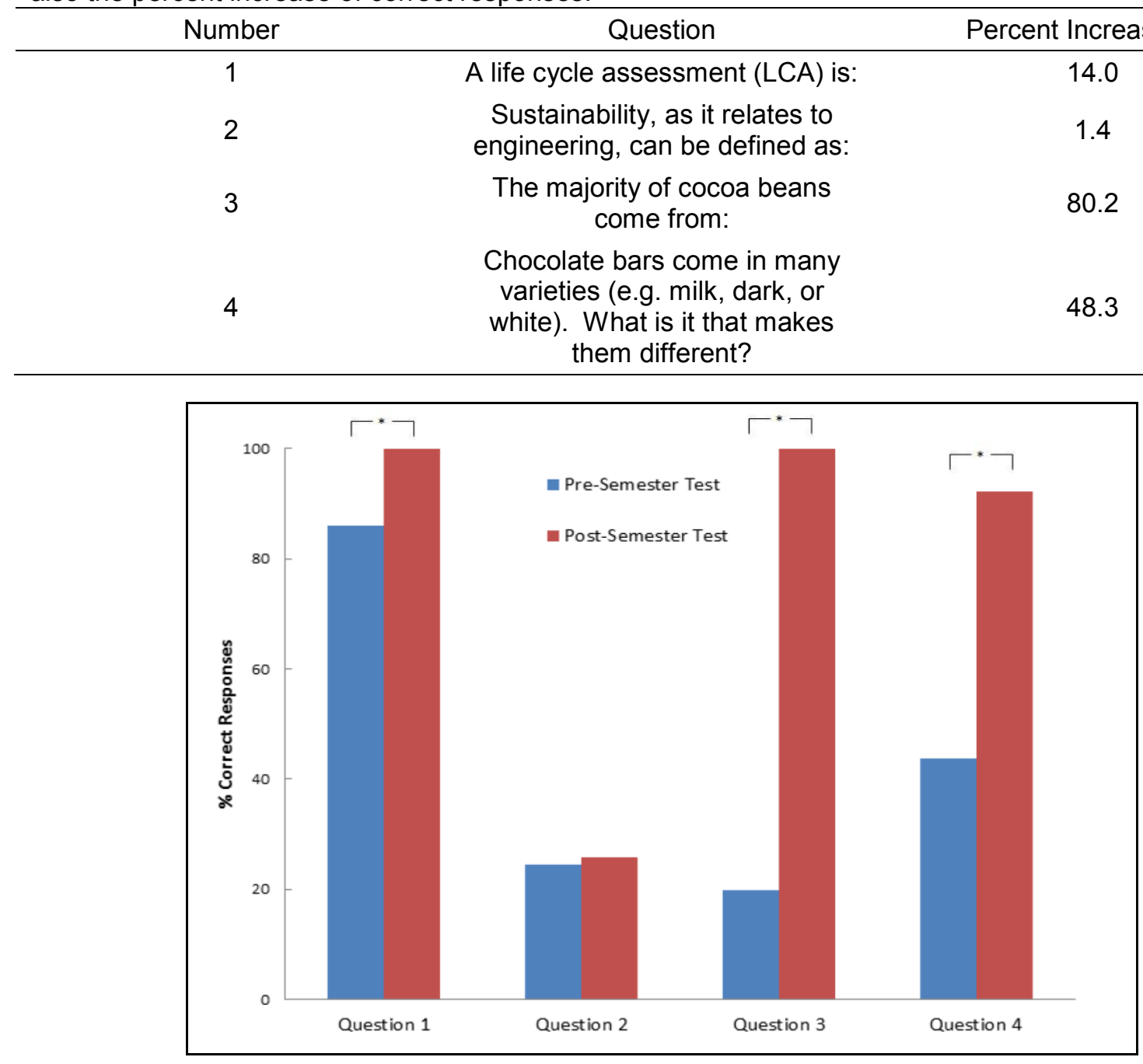

Figure 3. The percent of correct responses to the multiple-choice/true-and-false section of the assessment. The questions correspond to Table 2. The * symbol means that the pre-semester and postsemester results were considered statistically different, $p<0.05$.

\section{CONCLUSIONS AND FUTURE WORK}

To increase engineering students' knowledge about sustainability and socioeconomics, eight experiments were developed for use in a lower-level multi-disciplinary undergraduate lab-based course. These 
experiments focused on an area where socioeconomics concerns are important in the manufacturing of the product: chocolate truffles. To measure students' opinions and their gain in knowledge, an assessment was used at the beginning and end of the semester. From the Likert-Scale assessment data, it is evident that students felt more confident about their knowledge in sustainability and sustainable development topics, including the use of an LCA. The multiple-choice/true-and-false section demonstrated that the students' knowledge increased about sustainable development, socioeconomics, and related engineering concepts. This portion of the assessment also showed that while students had a high confidence in their knowledge of sustainability, they were unable to properly define it in regards to engineering. The inclusion of more time spent discussing sustainability and sustainable development with regards to engineering and editing experimental handouts to include more about these concepts are recommended to increase the effectiveness of the course at increasing student knowledge of global sustainable development.

\section{References}

Accreditation Board for Engineering and Technology. "Criteria for Accrediting Engineering Programs." Accreditation Board for Engineering and Technology. October 2, 2013.

http://www.abet.org/uploadedFiles/Accreditation/Accreditation Step by Step/Accreditation Documents /Current/2013_-_2014/eac-criteria-2013-2014.pdf (accessed November 30, 2014).

Afoakwa, E. O., A. Paterson, M. Fowler, and J. Vieira. "Effects of Tempering and Fat Crystallisation Behaviour on Microstructure, Mechanical Properties and Appearance in Dark Chocolate Systems." Journal of Food Engineering 89, no. 2 (2008): 128-136.

Brundtland, G.H. Our Common Future: World Commission on Environment and Development. New York: Oxford University Press, 1987.

Elnashaie, W. A. K. Wan Alina, M. S. Mohm Amran, A. B. Dayang Radiah, and A. Salmiaton. "Sustainable Development in Chemical and Biological Engineering Education." Procedia - Social and Behavioral Sciences 102, no. 1 (2013): 490-498.

Evans, G. M., K. P. Galvin, and E. Doroodchi. "Introducing Quantitative Life Cycle Analysis into the Chemical Engineering Curriculum." Education for Chemical Engineers 3, no. 1 (2008): 57-65.

Farrell, S., R. P. Hesketh, J. A. Newell, and C. S. Slater. "Introducing Freshmen to Reverse Process Engineering and Design through Investigation of the Brewing Process." International Journal of Engineering Education 17, no. 6 (2001): 588-592.

Farrell, Stephanie, and Eduardo Cavanagh. "An Introduction to Life Cycle Assessment with Hands-On Experiments for Biodiesel Production and Use." Education for Chemical Engineers 9, no. 3 (2014): 6776.

Fenner, Richard A., Charles M. Ainger, Heather J. Cruickshank, and Peter M. Guthrie. "Embedding Sustainable Development at Cambridge University Engineering Department." International Journal of Sustainability in Higher Education 6, no. 3 (2005): 229-241.

Giddings, Bob, Bill Hopwood, and Geoff O'Brien. "Environment, Economy and Society: Fitting them Together into Sustainable Development." Sustainable Development 10, no. 4 (2002): 187-196.

Guinée, J. B., et al. Handbook on Life Cycle Assessment: Operational Guide to the ISO Standards. Dordrecht: Kluwer Academic Publishers, 2002.

Hesketh, Robert P., C. Stewart Slater, Mariano J. Savelski, Kathryn Hollar, and Stephanie Farrell. "A Program to Help in Designing Courses to Integrate Green Engineering Subjects." International Journal of Engineering Education 20, no. 1 (2004): 113-123.

LaFraniere, Sharon. "Africa's World of Forced Labor, in a 6-Year-Old's Eyes." The New York Times, October 29, 2006: 1-6.

Nagle, Luz Estella. "Selling Souls: The Effect of Globalization on Human Trafficking and Forced Servitude." Wisconsin International Law Journal 26, no. 1 (2008): 131-162.

Perdan, Slobodan, Adisa Azapagic, and Roland Clift. "Teaching Sustainable Development to Engineering Students." International Journal of Sustainability in Higher Education 1, no. 3 (2000): 267-279. 